\title{
Spontaneous low cerebrospinal fluid pressure headache: an emergency medicine perspective
}

\author{
Justin S. Ahn, MD*; Cigdem Akincioglu, MD; Irene Gulka, MD; Grant Coome, MD*
}

\section{ABSTRACT}

Spontaneous low cerebrospinal fluid pressure headaches are a rare but treatable cause of debilitating headaches. The condition is characterized by a postural headache in the absence of any recent spinal procedures and is exacerbated when upright and relieved when supine. Diagnosis and treatment are often delayed, however, due to a lack of recognition and awareness, as illustrated by this case report of a patient who had multiple emergency department visits before further investigations were sought.

\section{RÉSUMÉ}

Une diminution spontanée de la pression du liquide céphalorachidien est une cause rare mais soignable de céphalées débilitantes. L'affection se caractérise par des céphalées orthostatiques, en l'absence de toute intervention rachidienne récente, qui s'intensifient en position debout et s'atténuent en position couchée. La pose du diagnostic et la mise en route du traitement sont souvent retardées en raison d'un manque de reconnaissance de l'affection et de prise de conscience de son existence, comme en témoigne le présent exposé de cas d'une patiente qui a consulté à plusieurs reprises au service des urgences avant que ne soit entreprise une exploration approfondie.

Keywords: low cerebrospinal fluid pressure headache, postural headache, spontaneous intracranial hypotension

Headaches are a common presentation in the emergency department (ED), accounting for up to $4.5 \%$ of all visits. ${ }^{1}$ Although only a small proportion of headaches have life-threatening etiologies, these causes must be ruled out in all patients before making a benign diagnosis, such as migraine or tension headache. Although the majority of headaches encountered will have benign causes, headaches can lead to an overreliance on analgesic medications and repeat physician visits and, most importantly, can have a considerable impact on an individual's quality of life and financial situation due to lost days at work. ${ }^{2}$

Spontaneous low cerebrospinal fluid (CSF) pressure headache (also known as spontaneous intracranial hypotension $[\mathrm{SIH}])$ is an important example of a significant, albeit rare, cause of severe persistent daily headaches. The headache is similar in presentation to post-lumbar puncture (LP) headaches and is caused by the spontaneous leakage of CSF. Unlike most benign headaches, however, spontaneous low CSF pressure headaches do not respond to analgesics. The curative treatment is repair of the leak. Small studies report that $\mathrm{SIH}$ is often misdiagnosed in the ED mainly due to lack of awareness of the condition. ${ }^{3}$

\section{CASE REPORT}

A 49-year-old female presented to her local ED after awakening from sleep with an acute posterior bilateral headache. It was associated with nausea, vomiting, and bilateral tinnitus and worsened with exertion. Overthe-counter analgesics were ineffective. She felt well the previous week and was otherwise a healthy and active individual on no medications. There was no previous history of headaches or head and neck trauma. She denied drug or alcohol use.

At the initial presentation, her vital signs were stable and she was afebrile. Her physical examination was unremarkable. No bloodwork was taken, but head computed tomography (CT) was performed and reported as normal. She received intravenous ketorolac, dexamethasone, metaclopramide, dihydroergotamine, diphenhydramine, and dimenhydrinate with

From the *Division of Emergency Medicine, Department of Medicine, †Division of Nuclear Medicine, Department of Medical Imaging, and $\ddagger$ Division of Radiology, Department of Medical Imaging, Western University, London, ON.

Correspondence to: Dr. Grant Coome, 800 Commissioners Road, E1-102, London, ON N6A 5W9; Grant.Coome@Ihsc.on.ca.

This article has been peer reviewed. 
minimal relief in the ED and was discharged home with a diagnosis of migraine. She returned to the ED two additional times over the next week with the same unrelenting symptoms and no change in her vital signs or physical examination. She was diagnosed with sinusitis and viral meningitis, respectively, and discharged home without further investigation.

Her headache persisted for 3 weeks and was severe enough to prevent her from ambulating, and she subsequently missed work. She was assessed for a fourth time in a tertiary care ED where, once again, her vital signs were stable and her physical examination was unremarkable. On further questioning, she stated that her headache was worse in the upright position and was relieved when supine, thus explaining her ambulatory symptoms. Magnetic resonance imaging (MRI) was ordered to evaluate the possibility of intracranial hypotension and to rule out cerebral venous sinus thrombosis. The MRI demonstrated diffuse dural thickening around the brain, with some downward slumping of the brain through the incisura, which was consistent with low CSF pressure (Figure 1).

She was admitted to Neurology where an LP revealed normal opening pressure of 80 to $90 \mathrm{~mm} \mathrm{H}_{2} \mathrm{O}$ (normal range $\left.65-195 \mathrm{~mm} \mathrm{H}_{2} \mathrm{O}\right){ }^{4}$ A radionuclide $\mathrm{CSF}$ leak study (cisternography) with hybrid imaging of singlephoton emission computed tomography-low-end computed tomography (SPECT-CT) was performed. A
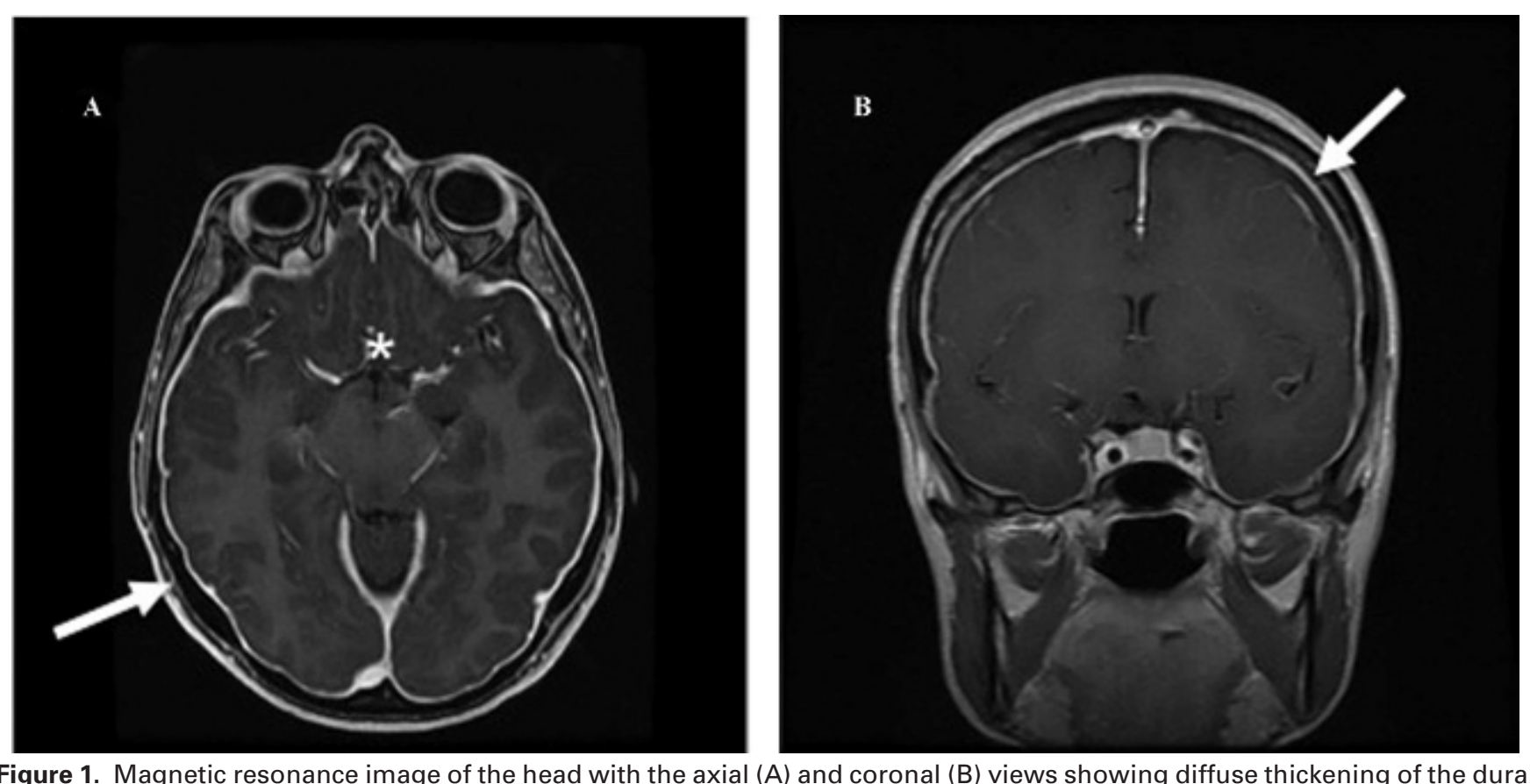

Figure 1. Magnetic resonance image of the head with the axial $(A)$ and coronal $(B)$ views showing diffuse thickening of the dural layer (white arrow) and collapse of the supracellar cistern (asterisk), suggestive of low cerebrospinal fluid volume.

prominent CSF leak was noted at the T1 level (Figure 2 ). The combination of the functional and anatomic data on SPECT-CT enabled visualization of additional sites of less prominent leak at the $\mathrm{C} 3$ and $\mathrm{T} 6 / \mathrm{T} 7$ levels. A blood patch was performed by anesthesia at the midthoracic spine. Postprocedure, her headache had resolved, and she was discharged home the following day. The headache had not returned at the 1-month follow-up, and she had returned to her premorbid level of activity. During her course in hospital, it was discovered that she works as an assistant at a chiropractic clinic and has frequent spinal manipulations performed. Notably, she had one 2 days before her symptoms started.

\section{DISCUSSION}

Spontaneous low CSF pressure headache is a rare condition. The estimated annual incidence is 5 per 100,000 , with peak age around 40 years and a female to male predominance of $2: 1 .^{5}$ Despite the classic history of a postural headache that is exacerbated when upright and relieved on recumbency, it is frequently missed. A 4-year observation study of a large urban ED identified 11 confirmed cases of SIH, none of which were diagnosed in the ED. ${ }^{3}$

The general accepted mechanism of SIH is CSF leakage rather than low CSF production. Leakages of 


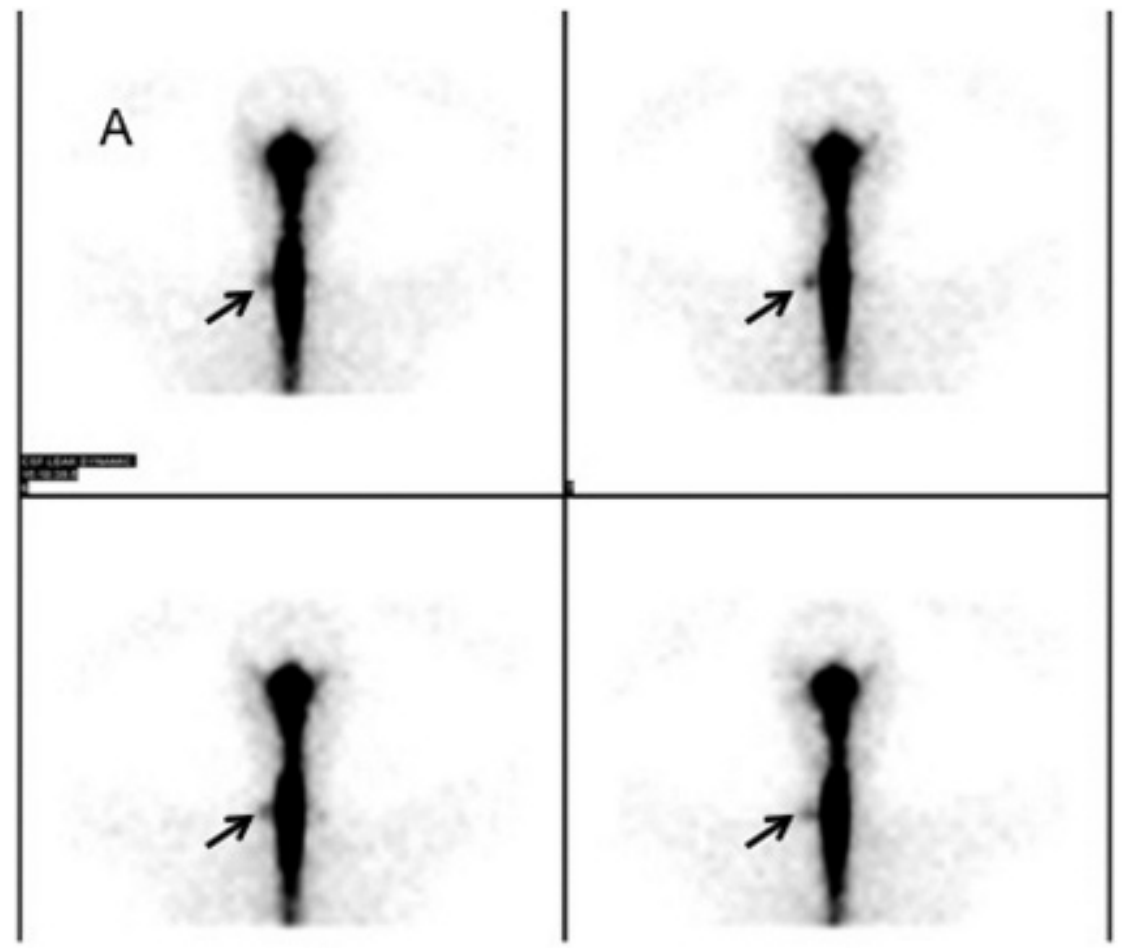

Figure 2. A radionuclide cisternography study 6 hours following the intrathecal injection of Tc-99m DTPA. Dynamic image acquisition was performed for 1 hour. This figure represents the sample frames, and the initial leak is identified at the right side of the cervical-thoracic region (black arrows).

CSF occur through defects in the dura mater. The decreased CSF volume causes the brain to sag, generating tension on the cerebral vessels and potentially compressing the brainstem or cranial nerves, giving rise to a myriad of neurologic symptoms. Due to gravity, the symptoms are exacerbated when the patient is upright and relieved in recumbency, giving rise to the classic postural component of this headache.

The etiologies of "spontaneous" dural tears are less clear. There may be minor or trivial trauma involved, such as falls, neck twisting, or sports activities that may cause the rupture of epidural cysts or perineural cysts or pre-existing defects from an underlying connective tissue disorder such as Marfan syndrome. ${ }^{6,7}$ In this patient, the etiology was unclear; however, it was likely related to recent chiropractic neck manipulation. There have been only two other case reports of low CSF pressure headaches secondary to chiropractic cervical spine manipulation. ${ }^{8,9}$

The nature of the headache itself is highly variable with respect to quality, location, and severity. The headache can last from weeks to years, and the orthostatic features may eventually disappear, resulting in chronic daily headaches..$^{10}$ Rarely, the headache can present without the postural component or have a paradoxical presentation with relief when upright. ${ }^{11,12}$ However, these cases of low CSF pressure headaches are highly atypical and will evade even the most experienced clinicians.

Criteria for the diagnosis of spontaneous low CSF pressure headache have been developed by the International Classification of Headache Disorders (ICHD) (Table 1). ${ }^{13}$ The criteria include a combination of historical, clinical, investigational, and therapeutic

Table 1. Diagnostic criteria for spontaneous low cerebrospinal fluid pressure headache

A. Diffuse and/or dull headache that worsens within 15 minutes after sitting or standing, with at least one of the following (and fulfilling criterion D):

Neck stiffness

Tinnitus

Hypacusia (enhanced sensitivity to everyday sounds)

Photophobia

Nausea

B. At least one of the following:

Evidence of low CSF pressure on MRI (e.g., pachymeningeal enhancement)

Evidence of CSF leakage on conventional myelography, computed tomographic myelography, or cisternography CSF opening pressure $<60 \mathrm{~mm} \mathrm{H}_{2} \mathrm{O}$ in the sitting position C. No history of dural puncture or other cause of CSF fistula

D. Headache resolves within $72 \mathrm{~h}$ after epidural blood patching

Adapted from Headache Classification Subcommittee of the International Headache Society. ${ }^{13}$

$\mathrm{CSF}=$ cerebrospinal fluid; $\mathrm{MRI}=$ magnetic resonance imaging . 
parameters to aid clinicians in diagnosis; however, one study found that only 3 of 90 patients (3\%) with MRIconfirmed SIH fulfilled all four diagnostic criteria. ${ }^{14}$ Thus, the diagnostic accuracy of these criteria has been challenged and new criteria are being proposed to encompass the wide range of disease presentations. ${ }^{14-16}$ The utility and practicality of these new criteria for diagnosing SIH in the ED will need to be studied.

In addition, the ICHD criteria state that CSF opening pressure is to be taken in the sitting position. Opening pressure measured sitting upright, however, may be falsely elevated and is not commonly practiced. ${ }^{17}$ New diagnostic criteria propose the removal of this requirement and favour using a low opening pressure $<60 \mathrm{~mm} \mathrm{H}_{2} \mathrm{O}$ regardless of position. ${ }^{16}$ Despite having low or even negative CSF pressures (that create a suction effect when entering the dural space), there have been no reported cases of herniation, and suspected or confirmed low CSF pressure headache is not a contraindication to LP. ${ }^{18}$ Some patients may even have normal opening pressure if they have intermittent leaks and/or a prolonged period of recumbency, as seen in this case. ${ }^{19,20}$ Although the opening pressure can aid diagnosis, it has largely been supplanted by neuroimaging tests, although it may still be performed prior to injection of contrast or radionucleotides during CT myelography or cisternography. ${ }^{5}$

The serious manifestations of spontaneous low CSF headaches are very rare and include quadriparesis, cerebellar hemorrhage, parkinsonism, chorea, and decreased level of consciousness. ${ }^{21-25}$ These severe complications will almost certainly require further imaging investigation where the underlying diagnosis of SIH may be made. Unfortunately, the majority of spontaneous low CSF pressure headaches encountered in the ED will present with vague neurologic complaints without any physical findings and are thus likely to be missed by the emergency physician, leading to a delay in diagnosis and treatment.

Once the cause of the headache is determined, initial management options are analogous to treating post-LP headaches, which include bedrest to avoid upright exacerbation of symptoms, oral hydration, and intravenous or oral caffeine (Table 2). ${ }^{5,26,27}$ Although these options have been used for decades, their effectiveness for spontaneous low CSF pressure headaches has not been established in well-designed, randomized, controlled trials. ${ }^{5}$ Oral and intrathecal steroids have

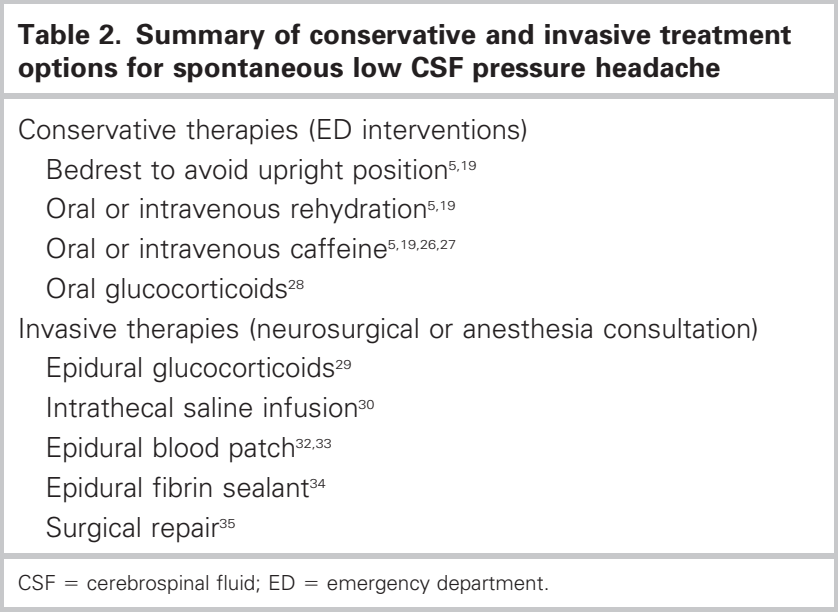

been reported to successfully treat SIH headaches, but their effectiveness remains uncertain. ${ }^{5,28,29}$ Other therapies, such as intrathecal infusion of saline, provide only transient symptomatic relief but have been used to stabilize an obtunded patient until definitive repair of the CSF leak could be performed. ${ }^{30}$

If conservative measures fail or the patient develops focal neurologic deficits due to the low CSF pressure, an epidural blood patch is recommended for definitive treatment. $^{20}$ Blood patching is performed by an anesthetist and involves the injection of autologous blood into the epidural space within the region of the leak. As the blood clots, it likely seals the dural tear. ${ }^{31}$ The success of blood patches varies from 52 to $87.1 \%$ and improves if the site of CSF leakage is identified, as was the case with this patient. ${ }^{32,33}$ Persistent cases may require neurosurgical consultation for fibrin sealants or surgical repair. ${ }^{34,35}$

The natural history and long-term outcomes of SIH are not well known as large prospective studies are lacking, likely due to the rarity of the condition and frequent misdiagnosis. MRI findings may correlate to headache resolution, which was seen in 25 of 26 patients $(97 \%)$ with abnormal MRIs compared to only 1 of 7 patients (14\%) with a normal MRI. ${ }^{36}$ Although headache recurrence has been reported between 7.7 and $28 \%$ and appears to be related to more invasive procedures (blood patching, surgery), it may also reflect more complicated patients who failed initial conservative therapy. ${ }^{5,19,37}$ The proportion of $\mathrm{SIH}$ patients who develop chronic daily headaches is unknown; in one study, 6 of 13 (46\%) patients experienced improvement with therapy yet continued to have a mild to moderate headache up to 2 years after symptom onset. ${ }^{10,37}$ 


\section{CONCLUSION}

Headache is a very common presentation in the ED, and although uncomfortable, the vast majority of causes are benign and will resolve over time. There are several life-threatening causes of headaches (e.g., subarachnoid hemorrhage, meningitis, among others) that must be considered before attributing the cause to other benign conditions, such as migraine or tension headache. This case of spontaneous low CSF pressure headache is a relatively rare cause of headache and highlights the diagnostic and physical toll on a patient for a potentially curable cause of debilitating headache. For patients who present with the typical postural headache and have a nondiagnostic CT scan, it is not unreasonable to obtain an MRI of the head either in the ED or on an urgent outpatient basis to confirm the diagnosis and arrange for appropriate consultation.

Competing interests: None declared.

\section{REFERENCES}

1. Ramirez-Lassepas M, Espinosa CE, Cicero JJ, et al. Predictors of intracranial pathologic findings in patients who seek emergency care because of headache. Arch Neurol 1997;54: 1506-9, doi:10.1001/archneur.1997.00550240058013.

2. Manzoni GC, Torelli P. Epidemiological classification and social impact of chronic headache. Intern Emerg Med 2010;5 Suppl 1:S1-5, doi:10.1007/s11739-010-0444-z.

3. Schievink WI, Maya MM, Moser F, et al. Frequency of spontaneous intracranial hypotension in the emergency department. I Headache Pain 2007;8:325-8, doi:10.1007/ s10194-007-0421-8.

4. Rando TA, Fishman RA. Spontaneous intracranial hypotension: a report of two cases and review of the literature. Neurology 1992;42:481-7, doi:10.1212/WNL.42.3.481.

5. Schievink WI. Spontaneous spinal cerebrospinal fluid leaks and intracranial hypotension. 7AMA 2006;295:2286-96, doi:10.1001/jama.295.19.2286.

6. Mokri B, Maher CO, Sencakova D. Spontaneous CSF leaks: underlying disorder of connective tissue. Neurology 2002;58: 814-6, doi:10.1212/WNL.58.5.814.

7. Ferrante E, Citterio A, Savino A, et al. Postural headache in a patient with Marfan's syndrome. Cephalalgia 2003;23:5525, doi:10.1046/j.1468-2982.2003.00587.x.

8. Suh SI, Koh SB, Choi EJ, et al. Intracranial hypotension induced by cervical spine chiropractice manipulation. Spine 2005;30:E340-2, doi:10.1097/01.brs.0000166511.59868.b7.

9. Beck J, Raabe A, Seifer $\mathrm{V}$, et al. Intracranial hypotension after chiropractic manipulation of the cervical spine. 7 Neurol Neurosurg Psychiatry 2003;74:821-2, doi:10.1136/jnnp.74.6. $\underline{821}$.
10. Grimaldi D, Mea E, Chiapparini L, et al. Spontaneous low cerebrospinal pressure: a mini review. Neurol Sci 2004;25 Suppl 3:S135-7, doi:10.1007/s10072-004-0272-x.

11. Mokri B, Aksamit AJ, Atkinson JL. Paradoxical postural headaches in cerebrospinal fluid leaks. Cephalalgia 2004;24: 883-7, doi:10.1111/j.1468-2982.2004.00763.x.

12. Liu H, Kaye A, Comarda N, et al. Paradoxical postural cerebrospinal fluid leak-induced headache: report of two cases. 7 Clin Anesth 2008;20:383-5, doi:10.1016/j.jclinane. 2008.01.011.

13. Headache Classification Subcommittee of the International Headache Society. The International Classification of Headache Disorders: 2nd edition. Cephalagia 2004;24 Suppl 1:9-160.

14. Mea E, Chiapparini L, Savoiardo M, et al. Application of IHS criteria to headache attributed to spontaneous intracranial hypotension in a large population. Cephalalgia 2008;29: 418-22, doi:10.1111/j.1468-2982.2008.01747.x.

15. Shievink WI, Maya MM, Louy C, et al. Diagnostic criteria for spontaneous spinal CSF leaks and intracranial hypotension. A7NR Am $\mathcal{F}$ Neuroradiol 2008;29:853-6, doi:10.3174/ ajnr.A0956.

16. Shievink WI, Dodick DW, Mokri B, et al. Diagnostic criteria for headache due to spontaneous intracranial hypotension: a perspective. Headache 2011;51:1442-4, doi:10. 1111/j.1526-4610.2011.01911.x.

17. Euerle BD. Spinal puncture and cerebrospinal fluid examination. In: Roberts JR, Hedges JR, Custalow CB, et al, editors. Clinical procedures in emergency medicine. 5th ed. Philadelphia: Saunders; 2010. p. 1111-2.

18. Schievink WI. Spontaneous spinal cerebrospinal fluid leaks: a review. Neurosurg Focus 2000;9:1-9, doi:10.3171/foc. 2000.9.1.8.

19. Schievink WI, Maya MM, Riedinger M. Recurrent spontaneous spinal cerebrospinal fluid leaks and intracranial hypotension: a prospective study. 7 Neurosurg 2003;99:8402, doi:10.3171/jns.2003.99.5.0840.

20. Malone RE, Love JN. Spontaneous intracranial hypotension: case report and relevant review of the literature. 7 Emerg Med 2007;32:371-4, doi:10.1016/j.jemermed.2006. 08.016.

21. Schievink WI, Maya MM. Quadriplegia and cerebellar hemorrhage in spontaneous intracranial hypotension. Neurology 2006;66:1777-8, doi:10.1212/01.wnl.0000218210. 83855.40.

22. Pakiam AS, Lee C, Lang AE. Intracranial hypotension with parkinsonism, ataxia, and bulbar weakness. Arch Neurol 1999; 56:869-72, doi:10.1001/archneur.56.7.869.

23. Mokri B, Ahlskog JE, Luetmer PH. Chorea as a manifestation of spontaneous CSF leak. Neurology 2006;67:1490-1, doi:10.1212/01.wnl.0000240059.96502.bf.

24. Pleasure SJ, Abosch A, Friedman J, et al. Spontaneous intracranial hypotension resulting in stupor caused by diencephalic compression. Neurology 1998;50:1854-7, doi:10.1212/WNL.50.6.1854.

25. Kashmere JL, Jacka MJ, Emery D, et al. Reversible coma: a rare presentation of spontaneous intracranial hypotension. Can $\mathcal{F}$ Neurol Sci 2004;31:565-8. 
26. Mokri B. Headaches caused by decreased intracranial pressure: diagnosis and management. Curr Opin Neurol 2003;16:319-26, doi:10.1097/00019052-200306000-00011.

27. Basurto Ona X, Martinez Garcia L, Sola I, et al. Drug therapy for treating post-dural puncture headache. Cochrane Database Syst Rev 2011;(8):CD007887.

28. Gentile S, Giudice RL, Martino PD, et al. Headache attributed to spontaneous low CSF pressure: report of three cases responsive to corticosteroids. Eur 7 Neurol 2004;11: 849-51, doi:10.1111/j.1468-1331.2004.00898.x.

29. Bel I, Moreno LA, Gomar C. Epidural dextran-40 and paramethasone injection for treatment of spontaneous intracranial hypotension. Can 7 Anesth 2006;53:591-4, doi:10.1007/BF03021850.

30. Bintler DK, Billon WP, Fishman RA. Intrathecal saline infusion in the treatment of obtundation associated with spontaneous intracranial hypotension: technical case report. Neurosurgery 2002;51:830-7.

31. Marcelis J, Silberstein SD. Spontaneous low cerebrospinal fluid pressure headache. Headache 1990;30:192-6, doi:10. 1111/j.1526-4610.1990.hed3004192.x.
32. Berroir S, Loisel B, Ducros A, et al. Early epidural blood patch in spontaneous intracranial hypotension. Neurology 2004;63: 1950-1, doi:10.1212/01.WNL.0000144339.34733.E9.

33. Cho KI, Moon HS, Jeon HJ, et al. Spontaneous intracranial hypotension: efficacy of radiologic targeting vs blind blood patch. Neurology 2011;76:1129-44, doi:10.1212/WNL. 0b013e318212ab43.

34. Schievink WI, Maya MM, Moser FM. Treatment of spontaneous intracranial hypotension with percutaneous placement of a fibrin sealant. Report of four cases. 7 Neurosurg 2004;100:1098-100, doi:10.3171/jns.2004.100.6. 1098.

35. Schievink WI, Morreale VM, Atkinson JL, et al. Surgical treatment of spontaneous spinal cerebrospinal fluid leaks. 7 Neurosurg 1998;88:243-6, doi:10.3171/jns.1998.88.2.0243.

36. Shievink WI, Maya M, Louy C. Cranial MRI predicts outcome of spontaneous intracranial hypotension. Neurology 2005;64: 1282-4, doi:10.1212/01.WNL.0000156906.84165.C0.

37. Kong DS, Park K, Nam DH, et al. Clinical features and long-term results of spontaneous intracranial hypotension. Neurosurgery 2005;57:91-6, doi:10.1227/01.NEU.0000163093. 38616.35 . 